\title{
EDITORIAL
}

\section{Our patients' fears may be getting the better of them: how do we deal with it?}

See linked articles by Partridge et al. on pg 315 and Sheridan et al. on pg 307

\section{*Alan Kaplana, Iain Small ${ }^{b}$}

a Chair, Family Physician Airways Group of Canada, University of Toronto, Canada

b Chair of the Executive Committee, Primary Care Respiratory Society UK; Centre for Academic Primary Care, University of Aberdeen, Aberdeen, UK

\section{*Correspondence:}

Dr Alan G Kaplan

17 Bedford Park Avenue

Richmond Hill,

Ontario

Canada

L4C $2 \mathrm{~N} 9$

Tel: +19058831100

Fax: +1 9058841195

E-mail: for4kids@gmail.com

Commissioned article Not externally peer-reviewed Accepted 8th July 2011

Online 22nd July 2011
Two research papers in this issue of the PCRJ focus on patients' fears in the context of obstructive airways diseases. ${ }^{1,2}$ These papers are both welcome and timely. Clinicians traditionally base their approach to COPD management on their concept of disease and its treatment, whereas patients perceive an illness which is impacted by their knowledge, fears and personal interpretations. ${ }^{3}$ Patient education can improve patients' ability to cope with illness ${ }^{4}$ and improve their response to COPD exacerbations. ${ }^{5.6}$ Co-morbidities of COPD include depression and anxiety, both of which are associated with fear, panic, social isolation, frustration and regret over past smoking behaviours. ${ }^{7.8}$ Patients with COPD may feel helpless ${ }^{9}$ and hopeless regarding the future; they know that their condition is progressive and nonreversible, and that no intervention will make a difference to symptoms and the likely final outcomes of respiratory failure and death.

Partridge and colleagues' studied patients from five countries in Europe regarding their attitudes to their asthma or COPD, using an established computerised questionnaire method that ensured a realistic spread of demographics and disease severity. Many respondents felt that their condition had a significant effect on their quality of life, with both stigma and emotional distress common. Medication-related issues included concern regarding side effects, and fears that medicines might lose their effect with time. Both relationship and knowledge gaps were clearly expressed, with patients feeling that their consultations were too infrequent and that the support they received from clinicians was incomplete. Interestingly, and with remarkable consistency, whilst clinicians received high scores from patients in communication skills and disease-specific knowledge, patient involvement in decision-making and psychological support scored poorly. Patients also reported a specific information gap around the purpose of, and side effects from, their medication. Little wonder, then, that patients frequently reported seeking information and support from other sources.

Sheridan and colleagues ${ }^{2}$ studied individuals with moderate to very severe COPD (at least two hospitalisations) in two New Zealand populations of differing ethnicity. These patients were all living with daily debilitating symptoms of breathlessness and fatigue. Analysis of how they interpreted this and how it affected their self-management and coping skills led to the emergence of three main themes:

a) Helplessness (in all groups), with passive resignation and poor self-management of their condition

b) Self blame with 'negative affect' (in one group) because the condition was caused by their smoking

c) Strong belief in God, Church and family (in the other group) with 'positive affect' which enhanced coping skills but not their ability to self-manage the condition.

These two articles provide the opportunity for us to review how we care for our patients overall. We must first evaluate our own attitudes towards patients with COPD. These include physician attitude, process of care, education, and our approach to the emotional component of the illness. Patients do recognise our subjective biases - especially when being told "it's your own fault" during discussions on smoking cessation... ${ }^{10}$ Their sense of hopelessness will clearly be worsened if we express ourselves in this way; yet if we can provide hope and realistic expectations such as improved quality of life and exercise tolerance, and reduction of exacerbations with guideline-based care, we can reverse this trend.

Patients clearly want to be reviewed by their physician, and yet we don't seem to meet their expectations. ${ }^{1,2}$ This should prompt us to consider how often we see patients for a 
routine asthma or COPD review when their disease is relatively controlled. Patients also feel that we should (and assume that we do) stay in contact with their hospital specialist - yet we know that a communication gap often exists. Patients' expectations, goals, fears or concerns need to be delineated in the context of shared decisionmaking on optimal care in order to ensure compliance. ${ }^{11,12}$ That being said, previous studies have found that patients with COPD have low levels of intentional non-compliance with medication, probably because they are chronically symptomatic. ${ }^{13}$ Fear of dyspnoea and feelings of vulnerability also appear to contribute to good compliance.

Most of the asthma patients in Partridge et al.'s study reported adjusting their regular therapy in relation to how they feel. ${ }^{1}$ We know that proper adherence is the key to long term control, so this message needs to be emphasised, 12,14-16 encouraging involvement in inhaler device choice and self-management to validate patients' involvement in their own care. But can patients access the best care? This is particularly important in COPD, where pulmonary rehabilitation (PR) plays a key role in treatment. Perhaps unsurprisingly, comprehensive access to PR was lacking in the populations studied by Partridge and Sheridan..$^{1,2}$ This is a key issue - and the authors highlight the potential for PR to identify and indeed fill the gaps in knowledge, skills and confidence that patients report. For example, we know that exercise in PR is able to correct some of the fear felt by people who have higher baseline levels of dyspnoea-related fear. ${ }^{17}$

As clinicians, we must recognise the need to support patients and help them manage their condition and lessen their associated emotional burden. We need to help them deal with helplessness and low affect, particularly when there is limited social support from family and social networks - factors negatively associated with managing illness. ${ }^{18}$ In this complex relationship, we must also acknowledge and accept those attitudes and beliefs held by our patients and the potential comfort or conflict that they bring. Finally, we need to understand patients' real fears, including terrifying things like dying of breathlessness or suffocation. ${ }^{19}$

Simpson and Rocker $^{20}$ divided COPD care into 'easy' scientificbased care and 'hard' patient-centred care which deals with individual patients' concerns. Unfortunately, it looks as though 'easy' COPD care - prescribing medications, for example - may not be as valuable as we think... ${ }^{21}$ The 'hard' care components - smoking cessation, comprehensive PR programmes, and more collaborative, supportive patient self-management plans that help with difficult realities like anxiety, depression, fatigue and social isolation - need to be attended to, and are often most appreciated by our patients. These two studies ${ }^{1,2}$ are a timely reminder to us to reconsider how we approach our patients, perhaps with a different model of interdisciplinary care to make the 'hard' care easier and thus relieve our patients' fears and hopefully some of their suffering.

\section{Conflicts of interest}

None.

\section{References}

1. Partridge MR, Dal Negrob RW, Olivieric D. Understanding patients with asthma and COPD: insights from a European study. Prim Care Respir J 2011;20:315-23. http://dx.doi.org/10.4104/pcrj.2011.00056

2. Sheridan N, Kenealy T, Salmon E, Read H, Raphael D, Schmidt-Busby J. Helplessness, self blame and faith may impact on self management in COPD: a qualitative study. Prim Care Respir J 2011;20:307-14. http://dx.doi.org/ 10.4104/pcrj.2011.00035

3. Kaplan A, Chapman KR. COPD patient education: physician and patient communication gaps. Prim Care Respir J 2011;20(2):A2. Abstract 043

4. Global Initiative for Chronic Obstructive Lung Disease: Global strategy for diagnosis, management and prevention of COPD (updated 2009). Available from: http://www.goldcopd.org

5. Wilkinson TM, Donaldson GC, Hurst JR, Seemungal TA, Wedzicha JA. Early therapy improves outcomes of exacerbations of chronic obstructive pulmonary disease. Am J Respir Crit Care Med 2004;169:1298-303. http://dx.doi.org/ 10.1164/rccm.200310-14430C

6. Bourbeau J, Julien M, Maltais $F$, et al. Reduction of hospital utilization in patients with chronic obstructive pulmonary disease: a disease-specific selfmanagement intervention. Arch Intern Med 2003;163:585-91. http://dx.doi.org/10.1001/archinte.163.5.585

7. Elkington $\mathrm{H}$, White $\mathrm{P}$, Addington-Hall J, Higgs $\mathrm{R}$, Pettinari $\mathrm{C}$. The last year of life of COPD: a qualitative study of symptoms and services. Resp Med 2004;98(5):439-45. http://dx, doi.org/10.1016/j.rmed.2003.11.006.

8. Emphysema Foundation for Our Rights to Survive (EFFORTS). Emotional burden of COPD - chronic bronchitis and empysema - may make patients reluctant to seek treatment, survey shows. 2006 [cited 20098 November]. Available from: http://www.emphysema.net/pressrel.htm.)

9. Omachi TA, Katz PP, Yelin EH, et al. The COPD helplessness index: a new tool to measure factors affecting patient self-management. Chest 2010;137(4):823-30. http://dx.doi.org/10.1378/chest.09-0764

10. Winstanley L, Daunt M, Macfarlane J. Doctors' attitude towards current smokers with chronic obstructive pulmonary disease and its impact on delivering smoking cessation advice. J Smok Cessat 2008;3(2):133-5.

11. Apter AJ, Reisine ST, Affleck G, Barrows E, Zuwallack RJ. Adherence with twicedaily dosing of inhaled steroids. Socioeconomic and health-belief differences. Am J Respir Crit Care Med 1998;157:1810-17.

12. Jones RCM, Hyland ME, Hanney K, Erwin J. A qualitative study of compliance with medication and lifestyle modification in COPD. Prim Care Respir J 2004; 13(3):149-54. http://dx.doi.org/10.1016/j.pcrj.2004.05.006

13. Horne R. Adherence to asthma medication: a question of ability? (editorial). Prim Care Respir J 2011;20(2):118-19. http://dx.doi.org/10.4104/pcrj.2011.00054

14. Haupt D, Krigsman K, Nilsson JL. Medication persistence among patients with asthma/COPD drugs. Pharm World Sci 2008;30:509-14. http://dx.doi.org/ 10.1007/s11096-008-9197-4

15. Haughney J, Fletcher M, Wolfe S, Ratcliffe J, Brice R, Partridge MR. Features of asthma management: quantifying the patient perspective. BMC Pulm Med 2007;7:16-24. http://dx.doi.org/10.1186/1471-2466-7-16

16. Howell G. Nonadherence to medical therapy in asthma: risk factors, barriers and strategies for improving. J of Asthma 2008;45:723-9. http://dx.doi.org/10.1080/02770900802395512

17. Janssens T, De Peuter S, Stans L, et al. Dyspnea perception in COPD: Association between anxiety, dyspnea-related fear and dyspnea in a pulmonary rehabilitation program. Chest 2011 Apr 14 PMID: 21493698

18. Halding A-G, Heggdal K, Wahl A. Experiences of self-blame and stigmatisation for self-infliction among individuals living with COPD. Scandinavian Journal of Caring Sciences 2011;25:100-07. http://dx.doi.org/10.1111/j.1471-6712.2010.00796.x

19. Gardiner C, Gott M, Small N, et al. Living with advanced chronic obstructive pulmonary disease: patients concerns regarding death and dying. Palliat Med 2009;23(8):691-7. http://dx.doi.org/10.1177/0269216309107003

20. Simpson A, Rocker GM. Advanced chronic obstructive pulmonary disease: rethinking models of care. Int J of Med 2008;101:697-704.

21. Pierson DJ. Translating new understanding into better care for the patient with chronic obstructive pulmonary disease. Respir Care 2004;49:99-109. 